\title{
Helen Salisbury: GPs are stretched too thin
}

\author{
Helen Salisbury GP \\ Oxford
}

Few people would disagree that general practice is at breaking point, buckling under the weight of expectation from patients and our political masters. Some GPs have responded by calling to remove home visiting from our contract. ${ }^{1}$ Many have diversified their teams, ${ }^{2}$ but it hasn't solved the problem.

The past 20 years have seen a shift of activity from secondary to primary care in many specialties. For example, when I first started, all patients using insulin were looked after by hospitals. Much of this shift is appropriate and convenient for patients, but it's come without the necessary funding: one widely quoted (but hard to pin down) statistic is that we carry out $90 \%$ of patient contacts for only $10 \%$ of the NHS budget. ${ }^{3}$ There has also been an increased focus on our role in health promotion and preventive medicine. Once, patients visited their GP if they were ill; now, many come to try to stay well. Isn't this a good thing?

Sometimes it is—screening for cervical cancers saves lives. ${ }^{4}$ Sometimes it isn't - the NHS health check is widely regarded as money poorly spent. ${ }^{5}$ But patients also come to see us about other problems in their lives. When we know that access to healthcare accounts for only $10 \%$ of the determinants of health, it encourages us to think more widely about what does make the difference, whether it's education, nutrition, smoking, exercise, environment, or (implicated in all of the above) poverty. The question that follows is: "What is it my job to fix?" My training is in diagnosing and treating illness. In the years since I qualified, I've learnt the skills I need to talk with patients about looking after their own health: how they might stop smoking, start exercising, or reduce alcohol intake. But I honestly don't know how to manage a social prescriber who might visit my patients to discuss therapeutic leisure activities.
It's not that I don't think this work should be done, just that it should not end up on the collective desk of GPs to organise and supervise. It's beyond our expertise, and we don't have the time. I want my disabled patients to have access to bus passes and parking permits, social housing for those in need, and benefits when they're too sick to work. These things can be more important to patients' mental and physical health than any intervention I can offer. But I don't think that it's the best use of scarce and expensively trained GPs to be spending time advocating for benefits that should be rights. I don't resent the patients who come to me requesting these letters and forms, but I am furious at a system that leaves GPs to pick up the pieces.

If we GPs were able to spend more of our time seeing patients, in the surgery or in their own homes, it might become a more attractive specialty and stem the flow of early retirements from the profession.

\section{Competing interests: See www.bmj.com/about-bmj/freelance-contributors.}

Provenance and peer review: Commissioned; not externally peer reviewed.

1 lacobucci G. GPs call for home visits to be removed from contract. BMJ 2019;367:16663. 10.1136/bmj.l6663 31757796

2 Health Foundation. Support staff and nurses from abroad plugging shortages in NHS workforce. 27 Nov 2019. https://www.health.org.uk/news-and-comment/news/supportstaff-and-nurses-from-abroad-plugging-shortages-in-nhs-workforce.

3 Full Fact. Wanted: a source for this widely used GP statistic. 1 Jun 2015. https://fullfact. org/health/wanted-source-widely-used-gp-statistic.

4 Mackie A. Update for primary care on cervical screening campaign. Public Health England. 21 Mar 2019. https://phescreening.blog.gov.uk/2019/03/21/update-for-primary-care-oncervical-screening-campaign.

5 Wise J. NHS Health Check programme wastes $£ 450 \mathrm{~m}$ a year, report says. BMJ 2015;351:h5039. 10.1136/bmj.h5039 26396137

Published by the BMJ Publishing Group Limited. For permission to use (where not already granted under a licence) please go to http://group.bmj.com/group/rights-licensing/ permissions 